\title{
High Risk Behaviors and Related Factors Among Addicts Admitted to Rehabilitation Centers in Southern Kerman, 2014
}

\author{
Ebrahim Noori, ${ }^{1}$ and Habibeh Ahmadipour ${ }^{1,{ }^{*}}$ \\ ${ }^{1}$ School of medicine, Kerman University of Medical Sciences, Kerman, IR Iran \\ "Corresponding author: Habibeh Ahmadipour, Social Determinants of Health Research Center, Institute for Futures Studies in Health, Kerman, IR Iran. Tel: 98-03433221660, \\ Fax: +98-03433221672, E-mail: ahmadipour@kmu.ac.ir
}

Received 2015 June 08; Revised 2015 October 10; Accepted 2015 December 01.

Keywords: Drug Users, Risk Behavior, Substance Treatment

\section{Dear Editor,}

Substance abuse refers to harmful use of psychoactive substances such as alcohol and illicit drugs. Use of psychoactive substances can result in behavioral, cognitive and physiological effects that make it difficult to control its use. According to the world health organization, at least 15.3 million persons have drug use disorders (1). Substance abuse disorders can be a predisposing factor for high-risk behaviors (HRB) (2), and risky sexual behavior and injection drug use (IDU) are common among addicts (3).

It is necessary to have sufficient information about HRB among drug users admitted to substance abuse treatment centers, so that our interventions can be focused on relieving these behaviors. This study was cross-sectional study carried out on 320 addicts admitted to rehabilitation centers in Southern Kerman, Iran, during 2014. Participants were selected through a multistage random sampling method. After obtaining permission, data was collected using recorded documents that contained demographic data such as age, gender, level of education, employment status and data about substance abuse duration, type and method. Data related to risky behaviors, such as history of tattoos, imprisonment, using shared needles and razors, and suspicious sexual relations were collected by phone or in-person interview. Assurance was given to all participants regarding confidentiality. Data was analyzed using the software package SPSS version 19.

Two hundred twenty-one (69.1\%) patients were males. The mean age of the participants was 37.50 years \pm 12.67 . One hundred thirty two (41.3\%) were illiterate and 196 (61.3\%) were unemployed (Table 1 ). The mean usage duration was $5.93 \pm 3.52$ years. The minimum duration of treatment was one month.

Opium (64.6\%) was the most common abused substance, and smoking (64.3\%) was the most common usage method, before admission.

Seventy-one (22.2\%) participants had at least one risky behavior. Thirty-three (10.3\%) had a history of tattoos, twenty-five (7.8\%) had a history of imprisonment, nine (2.8\%) used shared needles, six (1.9\%) used shared razors and three $(0.9 \%)$ reported suspicious sexual relations. There was no significant difference between men and women in the frequency of risky behaviors $(\mathrm{P}>0.05)$.

The mean age was $36.77 \pm 12.31$ and $40.02 \pm 13.67$ in the group with at least one risky behavior and in the group without it, respectively, and this was not significant ( $\mathrm{P}=$ 0.06). The frequency of at least one risky behavior was not significant based on education and employment status, usage duration, type and method. In multivariate analysis, only age had a statistically significant association with risky behavior $(\mathrm{OR}=1.02,95 \% \mathrm{CI}=1.001-1.043, \mathrm{P}=0.04)$.

We found that about a $25 \%$ of addicts had at least one HRB. In a previous study, Dastjerdi et al. found that $63 \%$ of addicts who were referred to an academic substance abuse treatment center had HRB (4), which was higher than our study. In the Dastjerdi study, the most commonly used substance was heroin, and it seems that risky behaviors are more prevalent among heroin abusers. We also found that HRB was higher in crack and heroin abusers, but the difference was not significant. Noohi et al. revealed that addicts had more experiences of drug injections, drug overdose and a history of being jailed (5).

Haque et al. found that high-risk sexual behaviors are prevalent among male drug users (6). In the present study, this risky behavior was lower. However, probably because of the stigma, its frequency is underreported.

We found no difference in the frequency of HRB between male and female addicts. Folch et al. also revealed "there were no gender differences in injecting risky behaviors." (7).

In Pakistan, "younger age, fewer education, lower income and having a temporary job were all associated with receptive needle sharing among IDUs." (8). We found that the mean age of the HRB group was lower than the non- 
Table 1. Comparison of Risky Behaviors Based on Education, Employment Status Type and Method

\begin{tabular}{|c|c|c|c|}
\hline \multirow[t]{2}{*}{ Variables } & \multicolumn{2}{|c|}{ Risky Behavior No. (\%) } & \multirow[t]{2}{*}{ P Value } \\
\hline & No & Yes & \\
\hline Level of education & & & 0.81 \\
\hline Illiterate & $104(78.8)$ & $28(21.2)$ & \\
\hline Middle school & $58(77.3)$ & $17(22.7)$ & \\
\hline High school diploma & $35(72.9)$ & $13(27.1)$ & \\
\hline University education & $52(80.0)$ & $13(20.0)$ & \\
\hline Employment status & & & 0.49 \\
\hline Unemployed & $155(79.1)$ & $41(20.9)$ & \\
\hline Employed & $94(75.8)$ & $30(24.2)$ & \\
\hline Drug type & & & 0.23 \\
\hline Opium & $113(75.8)$ & $36(24.2)$ & \\
\hline Resin & $121(81.8)$ & $27(18.2)$ & \\
\hline Heroin & $8(66.7)$ & $4(33.3)$ & \\
\hline Crack & $7(63.6)$ & $4(36.4)$ & \\
\hline Method of use & & & 0.81 \\
\hline Smoked & $177(78.3)$ & $49(21.7)$ & \\
\hline Injection & $10(83.3)$ & $2(16.7)$ & \\
\hline Oral & $62(75.6)$ & $20(24.4)$ & \\
\hline
\end{tabular}

HRB group, but the difference was not significant. Our study revealed that there was no significant relation between education and employment status and HRB.

In conclusion, HRB should be investigated and assistance should be provided to addicts in developing new behavioral skills in order to implement a harm reduction approach (9).

This study had several limitations. First, our study was carried out only on addicts admitted to rehabilitation centers. This could underestimate the frequency of risky behaviors. Also, our study was a cross-sectional study that limits examination of temporal relationships. Another limitation was that data collection was done using the participants' self-reports; this may not provide precise evidence. Lastly, probably because of the stigma of high-risk behaviors, its frequency has been underestimated.

The authors are grateful to all the staff and patients of the substance abuse treatment centers in Southeastern Kerman for their cooperation, which made this study possible.

\section{Acknowledgments}

The authors are grateful to all the staff and patients of the substance abuse treatment centers in Southeastern
Kerman for their cooperation, which made this study possible.

\section{References}

1. World Health Organization . Substance abuse 2015. Available from: http://www.who.int/substance_abuse/facts/en/.

2. Ryb GE, Dischinger PC, Kufera JA, Read KM. Risk perception and impulsivity: association with risky behaviors and substance abuse disorders. Accid Anal Prev. 2006;38(3):567-73. doi: 10.1016/j.aap.2005.12.001. [PubMed: 16426559].

3. Thurstone C, Salomonsen-Sautel S, Mikulich-Gilbertson SK, Hartman CA, Sakai JT, Hoffenberg AS, et al. Prevalence and predictors of injection drug use and risky sexual behaviors among adolescents in substance treatment. Am J Addict. 2013;22(6):558-65. doi: 10.1111/j.15210391.2013.12064.x. [PubMed: 24131163].

4. Dastjerdi G, Ebrahimi Dehshiri V, Kholasezade G, Ehsani F. Effectiveness of methadone in reduction of high risk behaviors in clients of mmt center. J Shaeed Sadoughi Unive Med Sci Yazd. 2010;18(3):215-9.

5. Noohi S, Azar M, Behzadi AH, Sedaghati M, Panahi SA, Dehghan N, et al. A comparative study of characteristics and risky behaviors among the Iranian opium and opium dross addicts. J Addict Med. 2011;5(1):748. doi:10.1097/ADM.0b013e3181db69ef. [PubMed: 21769050].

6. Haque N, Zafar T, Brahmbhatt H, Imam G, ul-Hassan S, Strathdee SA. High-risk sexual behaviours among drug users in Pakistan: implications for prevention of STDs and HIV/AIDS. J Pak Med Assoc. 2006;56(1 Suppl 1):S65-72. [PubMed: 16689489].

7. Folch C, Casabona J, Espelt A, Majo X, Merono M, Gonzalez V, et al. Gender differences in HIV risk behaviours among intravenous drug users in Catalonia, Spain. Gac Sanit. 2013;27(4):338-43. doi: 10.1016/j.gaceta.2013.02.006. [PubMed: 23578527]. 
8. Parviz S, Fatmi Z, Altaf A, McCormick JB, Fischer-Hoch S, Rahbar M, et al. Background demographics and risk behaviors of injecting drug users in Karachi, Pakistan. Int J Infect Dis. 2006;10(5):364-71. doi: 10.1016/j.ijid.2005.07.010. [PubMed: 16793307].
9. Grella CE, Anglin D, Annon JJ. HIV risk behaviors among women in methadone maintenance treatment. Subst Use Misuse. 1996;31(3):277301. [PubMed: 8834263]. 